\title{
Integrated Development Planning and Service Delivery in the Case of the Emfuleni Local Municipality in South Africa
}

\author{
Hulisani Cedric Mukwevho \\ University of Limpopo, P.O. Box 756, Fauna Park \\ Polokwane, 0787, South Africa \\ Oliver Mtapuri \\ University of Limpopo, P.O. Box 756, Fauna Park, Polokwane, 0787, South Africa \\ Email: simbaomtapuri@yahoo.com
}

\section{Doi:10.5901/mjss.2014.v5n23p45}

\begin{abstract}
Integrated Development Planning, as a new approach to local government, involves the entire municipality and its citizens in finding solutions to achieving good long-term development. The approach is developmental in nature. As such, integrated development planning presupposes extensive, inclusive, democratic participation of citizens. This article makes an exposition of a disjuncture between the integrated development processes and the participation of the citizens resulting in contested socio-economic and political terrains. Adopting a qualitative approach, and a sample of municipal officials, councillors, political parties and ordinary citizens, using unstructured face-to-face interviews, a focus group discussion and observation the study found out that under current conditions the level of engagement with the community is still not effective as communities are not involved during the various planning phases prior to the implementation of the plans; there is dissonance between targets set at lower and higher levels; mismatch between functions and allocated budgets; schism between growing needs and poor collection rates - all conspiring to encumber effective and efficient service delivery. The major contribution of this article is a model, the Municipal- Community Engagement for Effective Service Delivery, which states, inter alia, that for effective outcomes, align projects with community needs; strengthen the intergovernmental relations system; regularly provide feedback, communicate and interact with communities and establish a monitoring and evaluation unit as contextual prerequisites in the area under study.
\end{abstract}

\section{Introduction}

The Government of South Africa introduced Integrated Development Planning in local municipalities in 1998 as an interim integrated plan as such local municipalities in South Africa have to use "integrated development planning" as a method of planning for future developments in their areas. Apartheid planning left South Africa with cities and towns which had racially divided business and residential areas such that there are great differences in levels of service delivery between rich and poor areas coupled with sprawling informal settlements and spread-out residential areas which make it difficult to provide service delivery. Within that context, rural areas were left underdeveloped and largely unserviced.

Integrated Development Planning is an approach to planning that theoretically involves the entire municipality and its citizens in finding the best solutions to achieving good long-term development. The new approach to local government is developmental in nature with the purpose of overcoming the poor planning of the past.

An Integrated Development Plan is a super-plan for an area that gives an overall framework for development. It aims to co-ordinate the work of local and other spheres of government in a coherent plan to improve the quality of life for all people living in an area. It takes into account the existing conditions and problems and resources available for development. The plan should look at economic and social development for the area as a whole. It must set a framework for how land should be used, what infrastructure and services are needed and how the environment should be protected.

All municipalities must produce an Integrated Development Plan (IDP) in which it is responsible to co-ordinate the plan and draw in stakeholders from the area who can impact on and/or benefit from the development in the area. Once the IDP has been drawn up, all municipal planning activities and projects should be informed by the IDP including the annual council budget we should be based on it. It takes six to nine months to develop an IDP which has a lifespan of five years (linked directly to the term of office for local councillors) and is reviewed annually. The final IDP document has to be approved by the council (RSA, 2000). 
For the past years, the Emfuleni Local Municipality (ELM) has been involving its community during the IDP process. During the development of the initial IDP, the IDP term of reference was developed and is known as IDP process plan. The IDP process plan lays down the foundation for how the IDP review process will unfold. The process outlines the activities to be executed and timeframes during the review process. It identifies all the role players who participate, and the activities and duration of activities to be executed during IDP reviews. The process plan involves councillors, officials, ward committee, sector departments and the community as a whole as its participants in the development, planning and implementation of the IDP. The process plan also advocates for the establishment of an IDP representative forum, an IDP Steering Committee and various project task teams. It is still difficult to evaluate the effect of IDPs on developmental outcomes. There have, however, been a number of evaluations of IDPs sponsored by DPLG, GTZ and provincial government (Harrison, 2003). These evaluations point to modest success for IDPs even if many problems and challenges remain. They suggest that, increasingly, local authorities are beginning to shape the way they operate around the IDP and this may be leading towards more effective development local government (Harrison, 2003).

In the past nine years, there have been numerous protests and marches with regard to the state of service delivery in the Emfuleni Local Municipality. Members of the local community have written petitions complaining about the state of service delivery, the deterioration of infrastructure, and non-performance of the municipality. The Emfuleni Local Municipality has been adopting and approving its Integrated Development Plan since the inception of the concept in 1998 but the protests and marches continue, even though the Integrated Development Plan is considered a strategic tool or document that gives direction to the municipality and priority needs. There is, therefore, an apparent disjuncture between the IDP and the priorities of citizens, which has both social and political costs.

\section{Literature Review}

According to the Constitution of the Republic of South Africa (Section 152 and 153), local government is in charge of the process of development in municipalities and also of municipal planning. The constitutional mandate to municipalities, to relate their management, budgeting and planning functions to their objectives, gives a clear indication of the intended purpose of municipal integrated development planning. The Constitution also demands that local government must improve intergovernmental coordination and cooperation, to ensure integrated development across three spheres of government.

The White Paper on local government (1998) gives municipalities the responsibility to work with communities and groups within communities to find sustainable ways to meet their social, economic and material needs and improve their quality of life. The Municipal Systems Act 32 of 2000 (MSA) defines integrated development planning as one of the core functions of a municipality in the context of its developmental orientation. The MSA requires the IDP to be strategic and inclusive in nature. The IDP should link, integrate and coordinate other plans while taking development proposals into account. It should be aligned with the municipality's resources and capacity, while forming policy framework on which annual budgets are based. The integrated development plan must be compatible with national and provincial development plans and planning requirements.

\subsection{The planning system in South Africa}

The new planning system in South Africa is continuing to evolve through a learning process and in response to broader shifts in governance and macro policy approaches. Until recently, the IDP was seen almost entirely as an instrument of local planning and coordination (although there was a requirement that the IDP be aligned to national and provincial policies and programmes). However, from 1999, when Thabo Mbeki became president, the new emphasis was on integrated (or joined-up) multi-level governance. Issues of integration were a cornerstone of the second term of democratic governance under President Thabo Mbeki (Harrison, 2003).

Todes (2004) made an important contribution by evaluating the IDP in terms of its sustainability. Using the case of the Ugu District Municipality IDP in KwaZulu Natal, Todes found mixed outcomes. She concluded that "while the emphasis on integration and the multi-sectoral approach to development are strengths, greater attention needs to be given to environmental aspects, and the form of planning needs to be adapted to the context, and its social, economical and political dynamics" (Todes, 2004:843). The IDP has many of the strengths and flaws of other Third Way planning instruments. As an instrument of joined-up government it has been limited by its inability to involve and bind many other agents, apart from municipal government, that operate at the local level, although the emerging system of intergovernmental planning may address this issue. However, the IDP process has contributed to the development of networks and linkages, both formal and informal, within municipal structures and, to a lesser extent, between municipal 
structures and other agencies (Harrison, 2003).

As an instrument of participatory governance, the IDP has had mixed results. It has, undeniably, achieved a higher level of participation within municipal planning than ever before in South Africa's history (Adam \& Oranje, 2002) but there have been wide variations in the extent and success of this participation. Also, the participatory element of the IDP mixes uneasily with a performance management culture, driven by targets and time-frames, that is not really amenable to the often "messy", unpredictable and time-consuming processes of public participation (Adam \& Oranje, 2002).

A municipality must give effect to its Integrated Development Planning and conduct its affairs in a manner which is consistent with its Integrated Development Plan (RSA, 2000). According to the Constitution of the Republic of South Africa (1996), municipalities are responsible for the regulation, management and provisioning of the key municipal services within their respective demarcated geographical areas of jurisdiction. These include: beaches and amusement facilities; billboards and the display of advertisements in public places, building regulations; cemeteries; funeral parlours and crematoriums; child-care facilities; cleansing; control of public nuisances; control of undertakings that sell liquor to the public; decisions around land use; electricity and gas reticulation facilities; the accommodation, care and burial of animals; fencing and fences; fire-fighting services; and the licensing of dogs (Khosa, 2000).

The Municipal Systems Act (RSA, 2000) indicates that municipalities are specifically required to involve communities in the affairs of the municipality, to provide services in a financial and sustainable manner and to promote development in the municipality. The integrated development planning process requires an economic and spatial development component, promotion of participation and appropriate institutional and funding mechanisms based on international experience (Miguel, 2009). The IDP attempts to marry inclusiveness and participation with largely technocratic managerialism, and top-down control with bottom-up processes. In the end it may not prove satisfactory in relation to any particular objective, although it may justifiably be regarded as offering a reasonable balance or trade-off between objectives (Adam \& Oranje, 2002).

\subsection{Public participation}

According to Ababio (2007), participatory democracy means the provision of services based on the existence of a legislative framework that facilitates consultation, involvement and mobilisation of civil society in the formal process of policy making and implementation. Several pieces of legislation require some form of public participation in local government. Key amongst them is the Constitution of the Republic of South Africa, 1996. Sections 152 and 195 of the Constitution provide that the municipalities are obliged to encourage the involvement of communities and community organisations in municipal affairs; that people's needs must be responded to; and that the public must be encouraged to participate in policy making.

The White Paper on Local Government, 1998, describes developmental local government as "local government committed to working with citizens and groups within the community to find sustainable ways to meet their social, economic and material needs and improve the quality of their lives". The local government: Municipal Structures Act, 1998, gives metropolitan and local municipalities the option to establish ward committees as one of the specialised structures to enhance participatory democracy in local government. Municipalities must give effect to the provisions of the Act when establishing wad committees. The municipalities are required to annually report on the involvement of communities and community organisations in the affairs of the municipality. The Act stipulates that a municipality's executive mayor or executive committee has to give an annual report on the extent to which the public had participated in municipal affairs.

The Municipal Finance Management Act, 2003 encourages the participation of communities in the finances of municipalities, including the development of municipal budgets. The Municipal Property Rates Act, 2004 stipulates that members of the public must participate in the determination of municipal property rates. Moodley and Govender (2006) argue that municipal property rates also attempts to achieve equity in the local tax regime.

The level of participation - at least through legal channels - is but one indicator of the legitimacy of the South African local government system. As long as people consider it worth their time to participate, they are assumed to have some level of efficacy, and that they still consider the system as legitimate. I argue that the public voice serves as a reminder to leaders at the national, provincial and local spheres of government that the public has not only vested in them the mandate to lead, but also the responsibility to serve the public as well.

The Draft National Policy Framework on Public Participation, 2007 defines public participation as an open, accountable process through which individuals and groups within selected communities can exchange views and influence decision-making processes. It is further defined as a democratic process of engaging people in deciding, planning and playing an active part in the development and operation of services that affect their lives. From the various 
definitions, it seems that the definition of community participation is dependent on the context in which it is referred to. Public Participation is a mechanism designed to ensure that government is accountable, open and transparent in the periods between elections. It does this by ensuring that the government engages with the electorate between elections (Midgely, 1986).

Midgely (1986) states that the concepts of community participation which appeal to western, educated middle class activists do not conform to the expectations of ordinary people. For many people, community means sharing the benefits that others in society already enjoy. In the South African context, participation in municipal affairs takes place in terms of two main objectives. The first relates to upholding the principles and systems of participatory democracy and ensuring the legitimacy of the state in the local sphere through citizens being encouraged to participate in formal political processes such as elections. The second objective relates to local government's development mandate to alleviate poverty through service delivery and localised socio-economic development initiatives. These two objectives enable one to define participation cautiously as an inclusive process aimed at deepening democracy through formal participatory mechanisms and alleviating poverty through localised socio-economic development initiatives and improved basic service delivery (Ababio, 2006).

\subsection{Constraints to Public Participation}

Most, if not all, municipalities have challenges pertaining to the vast distances that have to be travelled due to the size of municipal areas. People are experiencing participation fatigue as they are tired of participating in their own development without seeing the meaningful benefits of their participation (Mafunisa \& Xaba, 2008). According to Mafunisa and Xaba (2008), there are misgivings with regard to the way the IDP process is managed, for example, bureaucratic red-tape and under-resourcing of the IDP participation structures, the municipality's inability to ensure the participation of the business sector in the IDP meetings at the local sphere. The IDP representative's structures appear inappropriate as there is lack of special efforts to ensure the participation of the non-organised, marginalised sections of the provincial inhabitants and groups. It is evident that creative ways should be formed to address these constraints. This will automatically improve the quality of public participation in the IDP process in the provinces (Mafunisa \& Xaba, 2008).

\section{Research Methodology}

The Emfuleni Local Municipality is one of three Local Municipalities of the Sedibeng District Municipality and extend along a 120 kilometre axis from east to west covering an area of $987.45 \mathrm{~km}^{2}$. Emfuleni is a largely urbanised municipality. The Emfuleni Local Municipality has approximately 4500 employees. The sample was drawn from municipal officials, the IDP Office, the Municipal Manager, the Engineering departments (which include the Roads, Water, Sanitation, Electricity and Housing departments), Ward Councillors, chairpersons of various political parties, organised and unorganised business structures and ordinary members of the community in which purposive sampling was used.

The sample consisted of 105 people who reside within the Emfuleni Local Municipality, namely, 20 officials, 20 councillors, 20 chairpersons of political parties in various wards, 20 represented organised and unorganised business structures and 25 ordinary citizens of the community. The rationale behind choosing such a sample was to get wide involvement of all stakeholders who reside in Emfuleni Municipal area as it was an evaluative study on the effectiveness of the IDP in service delivery. As such, officials responsible for the development, review and implementation of the IDP were important. Councillors are the voice of the community as they mediate between the municipality and the local community hence their inclusion. Chairpersons of various political parties were also involved to avoid bias towards the political party in power and also get the point of view of other political parties not represented in council sittings. Even though ordinary citizens are represented by Councillors, it is imperative to also establish whether or not their issues are well represented by their elected Councillors hence their inclusion.

In this investigation, a qualitative research approach was used in which unstructured face-to-face interviews were conducted, as they provided the advantage of soliciting or probing for more information. Observation was used in assessing the physical situation of infrastructure. Memoranda presented during service delivery protests were also collected and analysed. Data was also collected using focus group discussions to see areas of common understanding among the respondents.

Face to face interviews were conducted with the municipal officials. Semi- and unstructured, open-ended questionnaires were presented to councillors, chairpersons of various political parties, business formations and ordinary members of the community, so as to get a deeper understanding of their experiences, which structured instruments may not allow. A thematic approach was used, in which data was categorised, based on themes. These results are meant to 
contextualise rather than generalise to all municipalities because this evaluative study was qualitative in approach and therefore does not seek generalisation.

\section{Results}

\subsection{Community participation in the IDP process}

Between 2001 and May 2004, the community participation process was done in the form of an IDP Representative Forum, in which the key stakeholders were essentially Councillors and sector departments. The level of participation was in the form of information sharing rather than getting fresh ideas from the participants as the IDP document was only distributed to the participants during the gathering. The process was changed in September 2004 as the Municipality appointed an IDP Manager to drive the IDP process. As such, meetings were then classified according to regions and marginalised groups were also met separately from other stakeholders. Public participation became ward-based. Emfuleni Local Municipality has 43 wards. There is also the business breakfast attended by business people, NGOs, sector departments, ELM senior officials and the mayoral committee.

The designated groups or marginalised groups were met on their own and include women, people living with disability, youth and children. The ward-based type of meetings which mostly target ordinary members of the community, seem to have slightly improved the level of participation from the time the municipality was using consultants to drive the IDP review process and public participation meetings. The Speaker of the Council chairs all public meetings and the Executive Mayor talks to the community in all regions and all organised stakeholders.

Based on interviews with members of the community, despite the appointment of the IDP Manager, the level of engagement with the community has still not yet improved as such it became very clear that public participation is not effective. The modus operandi is such that the Executive Mayor presents the projects anticipated for the following year and the community is on.ly given an opportunity to raise their concerns or inputs and comments thereafter. The Executive Mayor may talk for more than 90 minutes but the community is only given less than thirty minutes to raise their concerns. Despite community dissatisfaction with the Municipal plan or IDP, their inputs are not taken into consideration. The plan will be implemented without taking into consideration their inputs. This municipality's IDP is failing to comply with the Municipal Systems Act no, 32 of 2000 as the Act requires that the plan be informed by the needs of the community. The concern in the whole process is that the community is not involved during the various planning phases prior to the implementation of the IDP. As a result, the projects are mostly determined by the line managers without the involvement of the community.

\subsection{Understanding the concept of the Integrated Development Plan (IDP): Perspective of officials}

From the twenty municipal officials who were interviewed, it became very clear that the concept of the IDP is a known concept in the municipality. There is a broadly clear understanding of an IDP as the municipality's five year strategic plan which drives service delivery and informs budgeting processes. Most of the officials had undergone training in IDP processes and had a clear understanding of the concept. However, besides the IDP department within the Emfuleni Local Municipality, all other departments such as Roads and Storm Water, Water and Sanitation, Waste Management, Finance and the political offices acknowledged that the manner in which IDP review process is being conducted leaves much to be desired. They voiced their frustration at the unrealistic time-frames given to submit the requested information to the IDP office, which ultimately informs the IDP document of the next financial year. One of the managers had this to say:

The process does compromise the end result, which is the IDP document, which is not reliable and credible and of course this also creates a wrong image of the municipality.

During a focus group with managers of ELM from the Departments of Roads and Storm Water, Electricity, Water and Sanitation, Housing, Budget, Internal Audit, Waste Management, it also became clear that IDP does indeed create immense expectations within the community as this reinforced by the way in which the municipality conducts its public participation. Great expectations are raised by the political statements uttered during those meetings, without necessarily verifying the municipal budget and IDP plans for those areas.

One of the managers claimed there were too many projects earmarked for implementation in the IDP within a very short period of time. In the past 10 years, Emfuleni's IDPs have identified more than 100 projects requiring to be implemented within 12 months. Despite the failure to implement all those projects for the particular year, the municipality continued to increase the number of projects for implementation in each year. The manager also added that targets set by National and Provincial government were not realistic. The local municipality is an implementing agency for national 
and provincial plans and strategies, However, some of the targets set at the national level do not consider the financial and human resources at the disposal of the local government. For example, some of the national government's targets include to halve the unemployment level and the tarring of all gravel road by 2014. The resources at local level do not match the targets set at national and provincial levels. He mentioned that the Municipality does not have enough cash, and as a result, it is impossible to meet targets and key performance indicators as set by both national and provincial governments.

\subsection{Unfunded mandate from national and provincial department}

Another manager mentioned that the national and provincial governments transfer some of their mandate or responsibility to local municipalities, nation-wide such as primary health. However, the transfer of such responsibility to local municipality does not consider the capacity and financial constraints at the local level. This, in turn, has affected the implementation and execution of the integrated development plan.

\subsection{Financial constraints}

During the focus group discussions with municipal officials, it emerged that the needs are far greater than the available resources. There is internal acknowledgement by the Emfuleni Local Municipality's officials that IDPs contain all the needs of the community but the challenge remains at the implementation stage due to financial constraints. Furthermore, the way in which the budget is compiled, always anticipates a higher collection rate than what the municipality can achieve. This has resulted in the yearly budget being adjusted downwards and has ultimately meant the cutting of both operational and capital budgets with a negative impact on the implementation of the Council's Integrated Development Plan.

According to officials from the Roads Department, the departmental budget was supposed to be increased annually in order for the department to meet some of the set targets, but instead, the budget is being reduced year after year. In 2008/09 the total budget was R 168 million and in 2009/10 it was reduced to R 150 million. The backlog especially for maintenance is increasing immensely while the budget to address the backlog is being reduced. Participants also revealed a number of financial constraints and problems limiting effective and efficient service delivery throughout the ELM, including administrative and bureaucratic difficulties in the accessing, application and implementation of the indigent policy system for free electricity, water and sanitation in all areas in a uniform manner. In the focus group discussions with the business fraternity, participants also raised the problem of delays in payment after services have been rendered. They indicated that according the ELM's supply chain management policy, service providers should be paid within 30 days of receipt of the invoice, but the ELM does not live up to its policy.

\subsection{Collection rate}

According to respondents, the municipality renders basic services such as water, electricity, refuse removal and others to the community. Despite this, the council does not collect enough rates and taxes to meet its service delivery obligations as reflected in the IDP. This has rendered the Emfuleni Local Municipality IDP merely a wish list. To compound the problem, in the focus group discussion with managers, it was reported that government funding is based on a backlog that is outdated as data collected in 2001 by Statistics South Africa (Stats SA), the official national statistics agency, is still the primary source used by municipalities for planning purposes as well as for the allocations of resources by the National Treasury. National government does not accept any data except those from Stats SA and this has contributed immensely to the financial constraints at municipal area level.

\subsection{Perspective of Councillors}

The councillors also echoed the same sentiments as officials. Ward Councillors also alluded to the fact that communities are engaged in the IDP process but that the challenge lies in the manner in which the public participation process is handled. For instance, they Lamented the manner in which senior politicians take the community for granted by indicating that year in and year out there is no visible service delivery at a local level. While a councillor acknowledged that the IDP indeed highlights the priorities of the council, projects to be executed each financial year and the three-year capital budget as well as the areas that need urgent or immediate attention, he claimed that what nullifies the process is the poor implementation of identified projects. 


\subsection{Perspective of members of the community}

There are contradictory views about its IDP. According to a member of the Sharpeville concerned residents, the needs of the community were not incorporated into the Municipal Integrated Development Plan. He stated that the Municipality is very good at raising the expectations of the community without necessarily delivering on their promises. Ward and PR councillors argued that the 2005/6 IDP was very comprehensive and identified almost all the needs of the community, but that the only challenge was with the implementation of the identified projects and the intentional omission or removal of the needs of the community during the review of the IDP each year, resulting in them not being implemented.

\subsection{Conflicting interests and contested grounds}

The officials perceive the so called "service delivery protests" as nothing other than internal political factions, whereas members of the community who were interviewed see municipal officials as lazy, corrupt and careless of their needs. A business Chamber of Commerce member was more concerned about enhancement of the local economy from awarding tenders to local business people than with service delivery. According to Councillors, service delivery protests are motivated by those who did not make it as either PR or ward councillors. They see it as a clear campaign to topple ward councillors. This, therefore, paints a negative picture of the state of service delivery. In an interview, a senior municipal official claimed: "The public uses service delivery protests as a scapegoat, whereas they have their own hidden agenda with people in leadership". However, some officials and Councillors, have indeed acknowledged that in some instances there are genuine service delivery protests. The research also established that members of the community need to be educated about the importance of paying for municipal services. The level of payment of rates and taxes is minimal, but the service delivery expectations are very high.

\subsection{Problems faced by the community}

The Department of Roads and Storm Water and others have acknowledged receiving petitions from the broader community regarding service delivery challenges and as well as about the bad state of roads across the municipal area. The following are the common complaints received by the Roads and Storm Water Department: gravel roads to be graded (Roshnee, Vanderbijlpark and Vereeniging), dangerous open storm water channels, potholes and road markings and people living with disability not considered when constructing roads. The community considers the local clinic to be too small; lack of drugs in clinic; lack of health facilities; lack of a mobile clinic; lack of recreational facilities; grading of soccer field; lack of sports facilities in Evaton; Residents are not happy about water leakages, bursting of old pipes, there is a need for basic water supply to the indigent, and the community wants the municipality to develop the wetland into a park, from Frikkie Meyer to Lebogang High School.

The residents also complain about the lack of a youth development strategy; one-stop service centre needed; theft of copper; lack of skills development centres; lack of housing; illegal extension of houses; housing backlogs; water-logged houses in extensions 11 and 14; poor living conditions in hostels; mushrooming of illegal informal settlements; need for housing in Kanana; outstanding 68 houses to relocate people from wetlands; and maintenance of low-cost housing in CW5. The residents also complain about illegal dumping, noise and air pollution caused by private firms and inconsistent refuse removal.Dissatisfaction arises from sewer spillages and blockages, street lights and high-mast lights not working, inconsistent traffic lights, continuous power cuts and unmaintained electrical infrastructures, the high rate of crime and limited police stations across the municipal area. Regarding finance, residents complain about incorrect billing, poor customer services and not enough pay points.

\subsection{Shifting the blame}

The challenges identified by ELM officials and councillors are similar to those outlined by the community at large, and centred on poor quality of work undertaken by contractors responsible for the construction of new facilities and/or maintenance and repair of existing facilities, most noticeable in the structural defects evident in recently constructed houses, deviation from agreed specifications and design flaws seen in a number of housing projects across the ELM, as well with respect to children's playground equipment. poor quality of workmanship was also noted in relation to the potholes that have yet to be fixed and roads that had only been partially gravelled.

Additional problems included the delays, blockages in the completion and/or abandonment of projects as a result of contractual, financial, design, capacity and human resource problems on the part of contractors and service providers. 
These obstacles need to be overcome to ensure efficient and effective service delivery that meets the needs of all members of the Emfuleni Local Municipality.

\subsection{Limited delivery regarding infrastructure development}

Participants pointed out that there are challenges related to infrastructure development surrounding housing, sanitation, and street lighting and that the quality, pace and extent of this work need to be increased. Housing was identified as the most important infrastructure challenge by ward councillors and community members at large, with a large backlog, problems surrounding the sharing of houses, slow pace of resettlement and contractor problems, incomplete projects, poor project management, and low quality of workmanship. Houses built in flood lines and unavailability of land for new developments were raised as a problem for infrastructure development across the entire municipal area, especially in the townships of Sebokeng, Evaton and Sharpeville.

The efficient and effective provision of safe and clean water to communities was also less than optimal, with communities pointing to a number of leaking water pipes and continuous blockage of sewer lines, an ineffective and inefficient water supply system where a single fault could negatively affect a number of neighbouring units, areas, suburbs and townships, the inaccessibility of water services and the limits on the amount of water provided to households. According to the community, the lack of sufficient community halls, clinics, crèches and other community facilities, as well as limited maintenance of existing community facilities were also indicators of poor service delivery.

\subsection{Lack of monitoring and evaluation, feedback and accountability}

There was also a lack of monitoring, evaluation and accountability, most noticeably in the housing arena, but also apparent in other areas of municipal delivery. Participants pointed to challenges around poor processes of engagement and communication; and confusion over the division of roles and responsibilities of the three spheres of government local, province and national. Respondents mentioned, for example, challenges concerning schooling and crime-fighting as significant problems in their communities. These are however, national and provincial competencies rather than municipal level concerns.

Although a number of projects had been initiated and work had commenced, the progress towards completion was often slow and delayed due to the lack of a coherent and consistent system of holding contractors and service providers accountable. In some instances, these projects had even been abandoned before they were completed.

As such, processes of engagement and communication with ELM officials and councillors also require significant improvement, due to the:

- Lack of material benefit actually accruing to communities despite promises of improved services, facilities and performance;

- Lack of follow-up on projects, the inaccessibility or invisibility of some ELM officials and councillors;

- Slow rate of response to complaints;

- Divide and rule tactics employed by some councillors, and

- The concurrent high degree of antagonism by community members towards ELM officials and councillors.

\subsection{Of progress and positive developments}

ELM Councillors and officials tended to confirm the progress noted by community members in building new facilities, and in the upkeep, maintenance and repair of existing facilities and infrastructure, with officials and councillors pointing to the extensive effort shown, funding provided and success achieved in the planning and implementation of projects. Some examples of positive developments include steady progress in bulk water supply in the informal settlement; the steadily increasing completed and ongoing housing delivery as implemented by Gauteng Provincial Department of Housing; eradication of the bucket system and the replacement of old sewer pump stations; upgrades and refurbishment of sport and recreation facilities, including George Thabe stadium in Sharpeville and Dickson park; tarring of main roads and other roads, repair of potholes and paving of sidewalks; maintenance and upgrading of numerous community halls and libraries across the municipal area, and construction of new community halls, including Bophelong and Sebokeng halls; expansion of electricity provision to new developments such as Tshepong and other newly developed areas, maintenance and repair of existing street light and high-mast lights; upgrading of electricity sub-stations. This reflected overall a good story to tell. 


\section{Towards a Model of Municipality-Community Engagement for Effective Service Delivery}

\subsection{Alignment of projects with community needs}

There should be a further engagement and interaction between the ELM and its community or rather individual wards before projects are decided upon and where community voices are heard and acted upon, in order to ensure that the projects undertaken are those that are deemed necessary by the communities.

- Project planning should be expanded to ward level, rather than at the macro-institutional level, thereby aligning projects with the needs of individual wards.

- Processes of considering the needs of local communities should be extended in the conception, design and implementation of ELM projects and operations.

- There should be a further engagement and interaction between the ELM and its community or rather individual wards before projects are decided upon and where community voices are heard and acted upon, in order to ensure that projects undertaken are those that are deemed necessary by the communities.

\subsection{Establishment of a monitoring and evaluation unit}

It is clear that there is vital need for the creation of a monitoring and evaluation unit dedicated to the regular consistent and coherent monitoring and evaluation of all projects, processes and service standards at the ELM, in the interest of effective and efficient service delivery, to ensure that projects and processes are completed on time, within the required budget and to the requisite standards of quality.

- In such a context, it is important that all aspects of ELM operations are monitored and evaluated, so as to avoid irregularities and to counter and rectify any problems that arise;

- The unit should at least be established under the Municipal Manager's office.

\subsection{Strengthen the intergovernmental relations system}

The ELM should extend, formalise and expand the systems and structures of cooperation with the other two spheres of government - provincial and national - to ensure the most efficient and effective utilisation of financial, physical and human resources.

- Clear roles and responsibilities must be defined for the three spheres of government to avoid misunderstanding over roles and spheres of influence;

- Funding should follow functions;

- There should be an integrated programme and schedule of meetings between the provincial, national and local politicians in order to avoid clashes of meetings;

- The ELM should extend, formalise and expand the systems and structures of cooperation with the other two spheres of government; that is provincial and national to ensure the most efficient and effective utilisation of financial, physical and human resources;

- There should be a greater alignment of budget and project cycles between the ELM and the two other spheres of government;

- This approach will therefore lead to lower levels of duplication, wastage and greater attention to meeting the service delivery needs of the ELM population.

\subsection{Regular feedback, communication and interaction with communities}

- The eight guiding principles of the "Batho Pele" philosophy of South Africa public sector representatives should be strengthened amongst all representatives of the ELM.

These systems and structures will ensure that there is regular and coherent participation and involvement of the community as far as possible.

\section{Conclusion}

Analysis of the public participation process, the Integrated Development Plan, service delivery protests and state of 
service delivery in Emfuleni has clearly shown that the Emfuleni Integrated Development Plan does not have significant impact on service delivery as service delivery is moving at a snail pace while the expectations are high on the side of the community.

Based on the above analysis, the Emfuleni Integrated Development Plan has not achieved the desired impact with regard to service delivery. Some of the challenges the Emfuleni IDP faces include downward adjustment of budgets; shortage of technical staff; financial constraints; lack of clear strategies in terms of collecting rates and taxes and reduction in the capital budget creating a disjuncture between planning and implementation. The intergovernmental relationship is not functioning properly resulting in sector departments not communicating well with the local municipality. As a result, the programmes of sector departments are running parallel to those of the municipality partly because of different financial years and even competition. All these factors have resulted in an IDP which is not implemented. In spite of all these challenges, admirable progress has been made by the ELM in improving the lives of its people resonating with a good story to tell. The successful application of the model suggested in this article, which is its major contribution, could facilitate efficient and effective service delivery for the betterment of the lives of the people of the Emfuleni Local Municipality.

\section{References}

Ababio, 2006. An investigation of community participation trends in the rural. University of Ghana, Ghana, Department of Public administration \& Health Services management.

Adam, A \& Oranje, M. 2002. A report on engagements with district and metropolitan municipalities on the first round of integrated development plans produced in terms of the Municipal Systems Act, 2000. Prepared for DPLG and the Municipal Demarcations Board. Pretoria.

Department of Provincial and Local Government. 2005. 2 ${ }^{\text {ND }}$ edition. An Integrated Development Plan Newsletter. Pretoria, DPLG.

Emfuleni Local Municipality. 2007/08. Annual Report. Vanderbij|park, Emfuleni Local Municipality.

Emfuleni Local Municipality. 2008/09. Annual Report. Vanderbij|park, Emfuleni Local Municipality.

Emfuleni Local Municipality. 2009/10. Integrated Development Plan. Vanderbijlpark. Emfuleni Local Municipality.

Harrison, P. 2003. Towards integrated intergovernmental planning in South Africa: The IDP as a building block. Report prepared for the DPLG and the Municipal Demarcations Board.

Mafunisa, MJ. \& Xaba, B. 2008. Public Participation and the Integrated Development Planning: the case of Limpopo Province. Journal of Public Administration, 43 (3.2): 452- 460.

Midgely, J. 1986. Community participation, social development, and state, Canada.

RSA, 2000. Municipal Systems Act 32 of 2000. Pretoria: Government Printers.

RSA, 1998. The White Paper on Local Government. Pretoria: Government Printers.

Statistics South Africa, 2001. Emfuleni demographic profile. Pretoria. Statistic South Africa.

The Constitution of the Republic of South Africa. Act 108 of 1996.Pretoria: Government printers

Todes, A. 2004. Regional planning and sustainability: Limits and potentials of South Africa's integrated development plans, Journal of Environmental Planning and Management, 47 (6):843-861 